IP Periodica Polytechnica Civil Engineering

\author{
59(2), pp. 1031072015 \\ DOI: $10.3311 /$ PPci.7538 \\ Creative Commons Attribution (1) \\ RESEARCH ARTICLE
}

\section{A Study of Swelling Behaviour in a Tunnel Using Finite Element Methods}

\author{
Masoud Cheraghi Seifabad, S. A. Sadrnejad, Dariush Ebrahimi
}

Received 27-05-2014, revised 26-11-2014, accepted 07-01-2015

\begin{abstract}
The aim of this research is to show swelling behaviour in a tunnel excavated through rocks by modeling them and using laboratory results. The engineering challenge is how to design a tunnel which contains swelling rocks such as marl. This aim is achieved through two methods. In the first method, the Field System Solution program (FISS) is calibrated using experimentally obtained laboratory graphs of the saturated rocks around the tunnel, and the parameters are applied to the geometry of the tunnel. Comparing a critical state model with stresses around the tunnel, stability of the rocks was examined. In the second method, stability of the rocks around the tunnel was investigated by using the Nisa-II program, adjusting the laboratory swelling graphs with the creep function to the program and, finally, drawing Von Mises stresses around the tunnel.
\end{abstract}

\section{Keywords}

Tunnel $\cdot$ Swelling $\cdot$ FEM $\cdot$ Rock properties

\section{Masoud Cheraghi Seifabad}

Department of Mining Engineering, Isfahan University of Technology, Isfahan, 84156-83111, Iran

e-mail: cheraghi@cc.iut.ac.ir

\section{S. A. Sadrnejad}

Dariush Ebrahimi

Department of Civil Engineering, Khajeh-Nasiroddin Toosi University, Tehran, 470 West Mirdamad Ave, Iran

\section{Introduction}

Phenomena such as swelling, squeezing, creep and consolidation may result in the movement of rocks around the tunnel over time. The increase in movement velocity and displacement magnitude often vary in the tunnel face depending on geological conditions, the principal stress orientations and tunnel shape. Certain types of rocks such as clay minerals and anhydrite tend to undergo volume change as a result of changes to their moisture content. Supports placed in tunnels excavated in such rocks experience cycles of increased and decreased pressures depending upon the wetting and drying cycles. Rocks with swelling potential develop shrinkage cracks from alternating wet and dry conditions. Although the volume increase can be controlled by lining the tunnel, swelling pressures on the lining can be damaging. Tests are conducted to estimate the swelling impact of mechanical behaviour. Significant efforts have been made by many researchers, in particular by members of the Commission on Swelling Rock of the International Society for Rock Mechanics [1-12]. Recent research has shown how triaxial tests can be used to quantify the swelling properties of the ground [13]. Lo et al. [10] have done extensive research on mechanical properties of bed rock in downtown Calgary, Canada. In this paper, the swelling phenomena are described and the effect of swelling on the tunnel is investigated. The tunnel in this paper is located near the Pashakola Dam in the Mazandaran province in the north of Iran.

\section{Geological Conditions}

The type of ground is cretaceous marl consisting of ammonites. Marl has a dark grey color with no specified bedding.

\section{Laboratory Tests}

Laboratory tests were based on samples obtained from the boreholes. All samples were cretaceous marl. Test results from three samples of marl indicated that the carbonate calcium content was $40 \%$.

In a free-swelling test, each sample was placed in a container and submerged in distilled water [14]. The vertical displacement (swelling strain) was measured using an oedometer. Determina- 
tion of the swelling pressure (stress) is also important. The axial displacement was fixed by tightening screws to measure the swelling pressure (stress). The specimens were $55 \mathrm{~mm}$ in diameter and $20 \mathrm{~mm}$ in thickness. The maximum recorded swelling pressure was $120 \mathrm{kN} / \mathrm{m}^{2}$. Also, as the swelling potential and the free swelling graph were calibrated together, the time domain should be adjusted to the recorded data intervals. Results given in Fig. 1 confirm that the marl can be treated as visco-elastic material. Standard triaxial tests have also been conducted and the relationship between the effective stress and axial stress is shown in Fig. 2. The curve represents critical stress conditions.
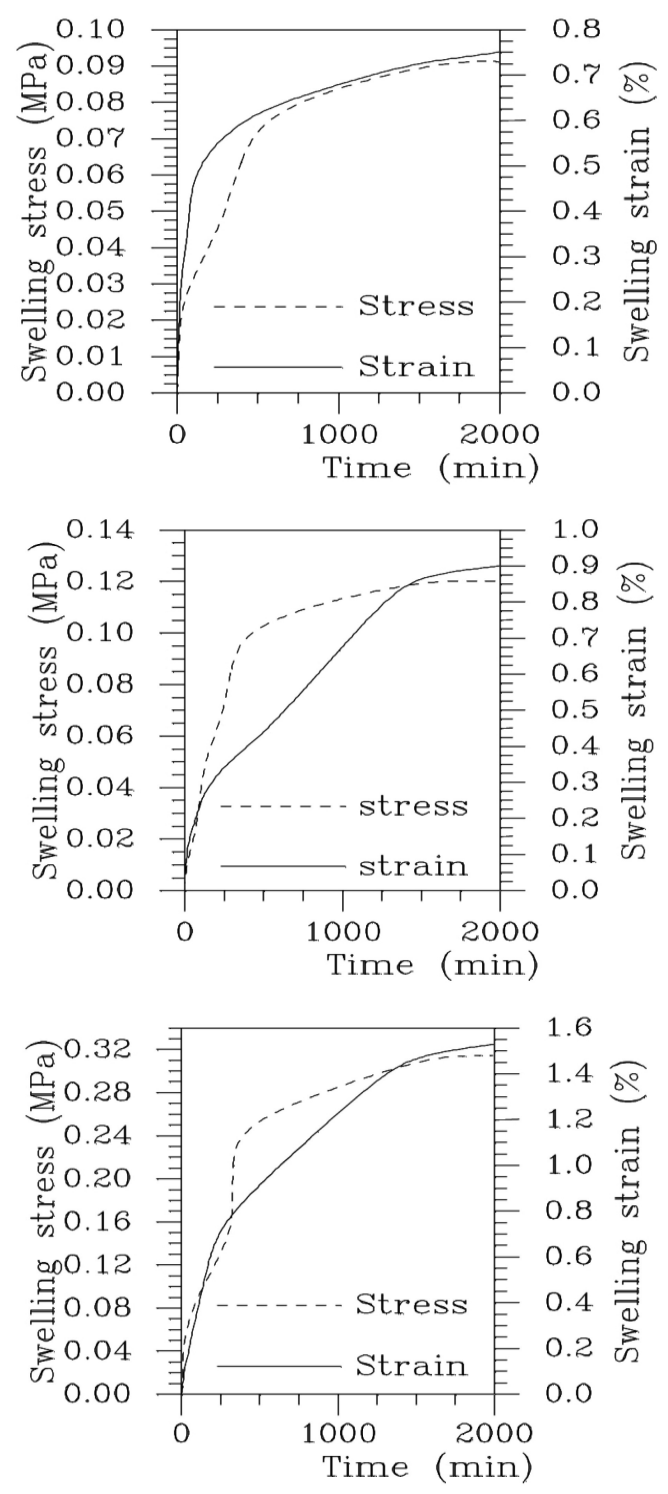

Fig. 1. Laboratory swelling tests

\section{Swelling Assessment around the Tunnel Using Nu- merical Methods}

Two programs were used for the analysis: FISS and Nisa-II.

The FISS program models two-dimensional non-linear viscoelastic-plastic behaviour. It can also be used for visco-elastic behaviour. As a result, this model was applicable to the particular case under examination and is suitable for analysis of

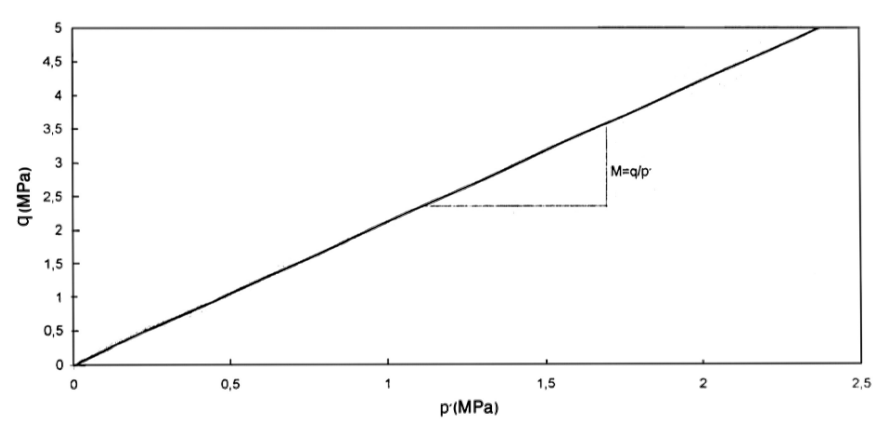

Fig. 2. Critical state

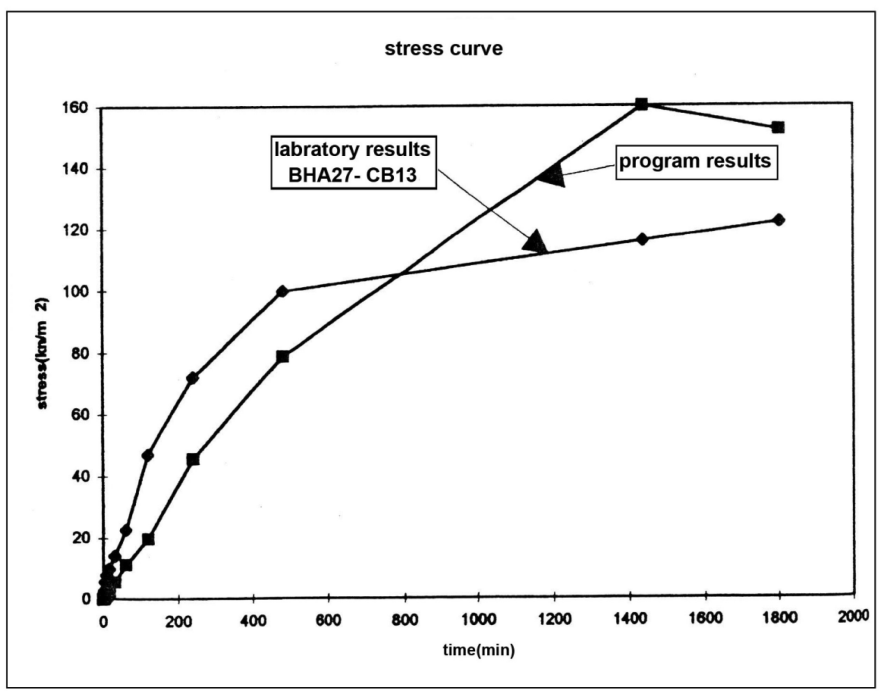

Fig. 3. Calibration of Free-Swelling Test

swelling around the tunnel. To utilize the program the following conditions should be met:

1 Time intervals, total time in free swelling and potential swelling should be equal. As can be seen, the free-swelling graph is in the same time length of 2000 minutes as the potential swelling graph.

2 The constrained conditions in program should in accordance with the test conditions.

3 It is advisable that the selected parameters should be in the acceptable domain for the materials.

4 The graphs are to be simultaneously modeled when running the program.

The critical state concept is an idealisation of the observed behaviour of clays and other similar materials in triaxial tests. The relationship between the mean effective stress p', $\left[\frac{1}{3}\left(\sigma_{1}^{\prime}+2 \sigma_{3}^{\prime}\right)\right]$, and deviatoric stress $\mathrm{q},\left(\sigma_{1}^{\prime}-\sigma_{3}^{\prime}\right)$, is shown in Fig. 22 (which shows the critical state in triaxial testing) where, $\sigma_{1}^{\prime}$ and $\sigma_{3}^{\prime}$ are the effective principal stresses. Based on the triaxial tests the stresses are $\sigma_{1}^{\prime}=5 \mathrm{MPa}$ and $\sigma_{3}^{\prime}=0.7 \mathrm{MPa}$.

All critical states forming a unique line are referred to as the Critical State Line defined by the following equation:

$$
q=M p^{\prime}
$$


where $M$ is a constant.

The results given in Fig. 1 for marl samples collected from the boreholes at the tunnel site were used for the analysis. Laboratory results are compared with the program results using Fig. 3 and Fig. 4 As seen, there is little discrepancy between the theoretical and practical results. It is necessary to draw the negative pore pressure distribution curve with time. Fig. 5 gives such a curve where it can be seen that the pore pressure tends to reach zero with time which justifies the swelling behaviour.

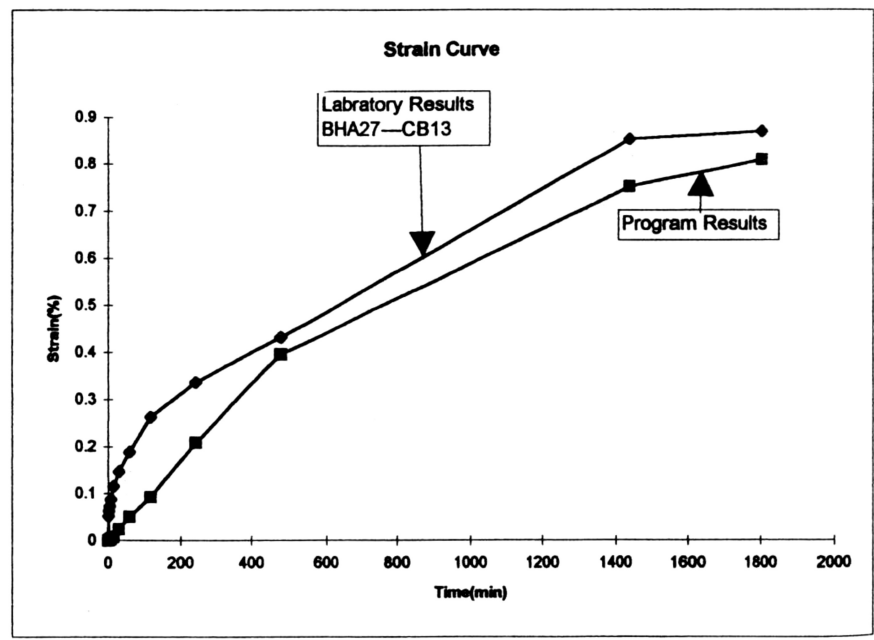

Fig. 4. Calibration of Swelling Pressure Test

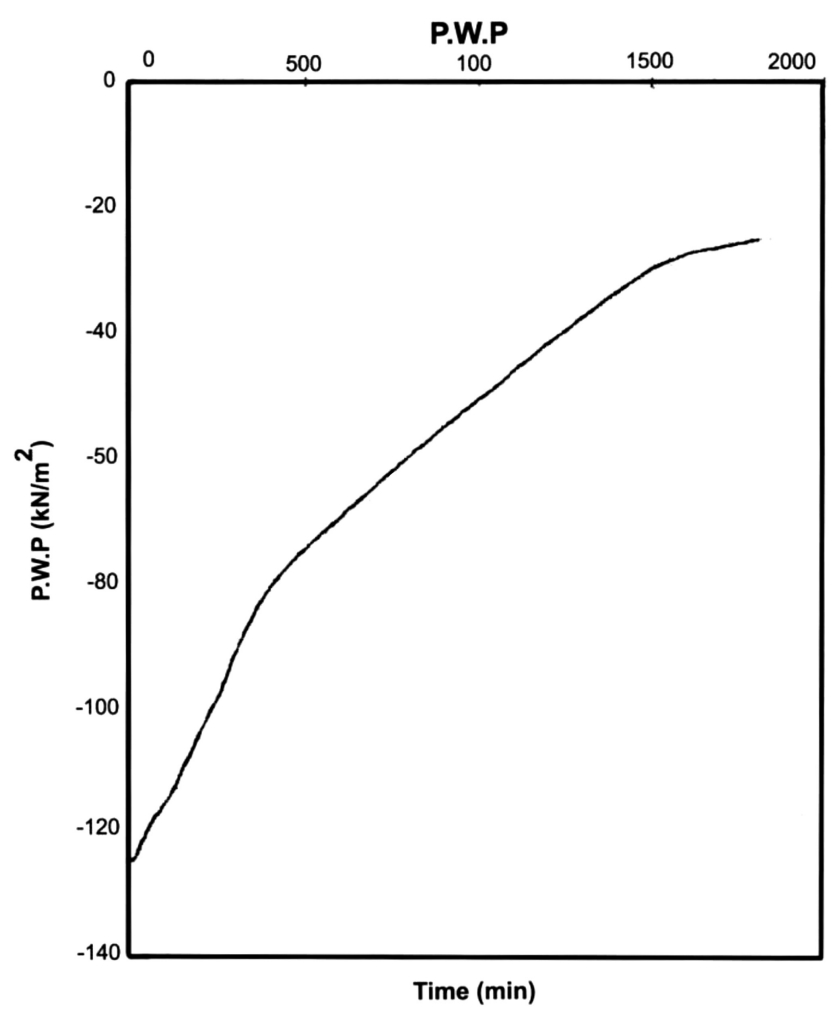

Fig. 5. Pore Water Pressure Distribution Curve

After calibration of the program using these the graphs, the following properties were determined for the marl:

Modulus of elasticity, $E=1 \mathrm{GPa}$ Poisson's ratio, $v=0.24$ The unit weight, $\gamma$ of the marl is $0.0231 \mathrm{MN} / \mathrm{m}^{3}$ The uniaxial com- pressive strength of the marl, $\sigma_{c}$ is $3.19 \mathrm{MPa}$

The tunnel has the following key characteristics: depth $100 \mathrm{~m}$, diameter $5 \mathrm{~m}$. The section of the tunnel shown in Fig. 6 was chosen from the geometry of the tunnel. The swelling marl is around the perimeter of the tunnel [15]. Compressive stresses are effective in the range of the tunnel radius, the boundary was selected as the tunnel diameter composed of marl, and only this part is divided into elements accurately.

All the elements are susceptible to water during swelling completion and at the time of excavation the swelling is accomplished. For safety reasons, this is the most critical state.

The program determines the maximum and minimum principal and shear stresses. The comparison of stresses around the tunnel with strengths highlights the plastic zone illustrated in Fig. 7. The conditions of the rocks around the tunnel are investigated according to the failure criterion of the Critical State which is $M=q / p^{\prime}$. The conditions of the sidewalls are more critical than the roof and floor.

\section{Comparison of FISS with Nisa-II Results}

It was necessary to compare the FISS program results with a different technique. The control is to compare these results with a program which considers time-dependent behaviour. For this, the Nisa-II software [16] was utilized to model creep behaviour. The creep curve shows 3-D visco-elastoplastic behaviour stress, strain and time. For this analysis, both linear and non-linear conditions were considered. In non-linear conditions, different models are presented for the failure condition (yield function). Therefore, only the Von-Mises model was selected. The model which defines creep in the Nisa-II program is as follows (Eq. (1)):

$$
\varepsilon^{\mathrm{C}}=\left(A \sigma^{\mathrm{B}}\right)\left(C \cdot t^{\mathrm{D}}\right)
$$

where A, B, C and D can be obtained from Eq. (2) and Eq. (3); $\varepsilon, \mathrm{t}$ are strain and time respectively.

Strain is defined by the product of stress and time functions. Two functions are obtained for stress and strain from the borehole results. One borehole, sample BHA27-CB13, was selected as a representative sample. Stress and strain were calculated as follows (Eq. (2) and Eq. (3)):

$\varepsilon=A . t^{B} \Rightarrow\left\{\begin{array}{c}0.001474=A(1800)^{B} \\ 0.008526=A(86400)^{B}\end{array} \Rightarrow\left\{\begin{array}{c}A=0.4503 \\ B=5.04 \times 10^{-3}\end{array}\right.\right.$

$$
\sigma=C . t^{D} \Rightarrow\left\{\begin{array} { r l } 
{ 1 4 0 8 0 } & { = C . ( 1 8 0 0 ) ^ { D } } \\
{ 1 1 5 9 2 0 } & { = C . ( 8 6 4 0 0 ) ^ { D } }
\end{array} \Rightarrow \left\{\begin{array}{c}
C=0.5446 \\
D=237.615
\end{array}\right.\right.
$$

By substituting the values in the above-mentioned formulas, the following function is described for the strain (Eq. (4)):

$$
\varepsilon=\left(4.208 \times 10^{-3} \sigma\right) \times\left(5.04 \times 10^{-5} t^{-0.094}\right)
$$




\begin{tabular}{|c|c|c|}
\hline 25 & 26 & 27 \\
\hline 22 & 23 & 24 \\
\hline 19 & 20 & \\
\hline 17 & 18 & \\
\hline 15 & 16 & \\
\hline 12 & 13 & 14 \\
\hline 10 & 11 & \\
\hline 7 & 8 & 9 \\
\hline 4 & 5 & 6 \\
\hline 1 & 2 & 3 \\
\hline
\end{tabular}

Fig. 6. Tunnel Cross-Section

By introducing the above creep function in the Nisa-II program, the maximum principal stresses are obtained.

It is possible to obtain the Von-Mises stresses by using the above-stated values in Nisa-II program. As the Von Mises stresses are calculated in the Nisa-II program, it is necessary to compare these stresses with the Von-Mises failure criterion, to be calculated by the relationships mentioned above and the maximum principal stresses of rock obtained from triaxial tests. As a result, it is possible to specify the rocks around the tunnel (see Fig. 8 and Fig. 9). As seen, in this model the sidewalls show more critical conditions than the roof and floor.

\section{Concluding remarks}

This research is based on laboratory findings and numerical methods. Two separate methods were utilized to model the swelling behaviour. In the first method, the required parameters were obtained and then applied to the program using the swelling graphs. In the second method, using swelling graphs the stress-strain-time curve was drawn. In other words, the strain function is defined by the stress function over time. Finally, in addition to controlling the work, a comparison of the different models was made. It is emphasized that the findings need to be verified by monitored data. Once stress conditions around the tunnel have been determined, tunnel lining design can be customized.

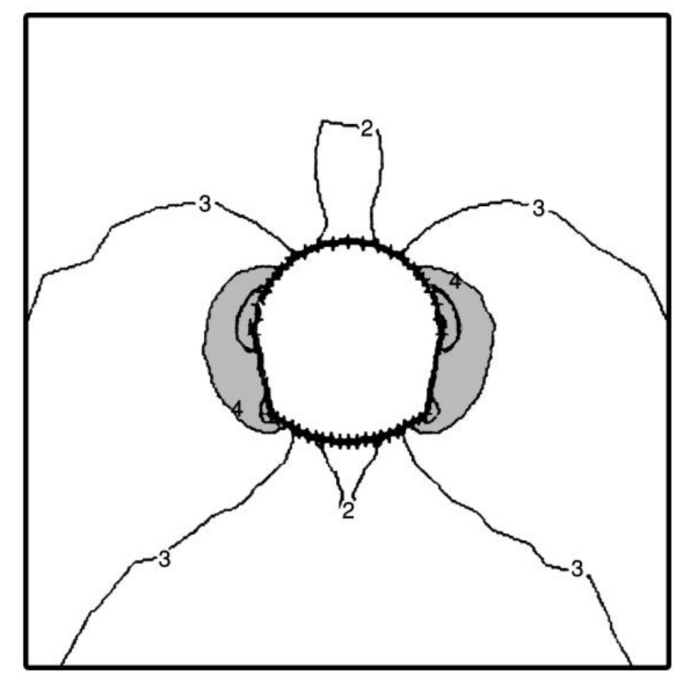

Fig. 7. Failure According to Critical State

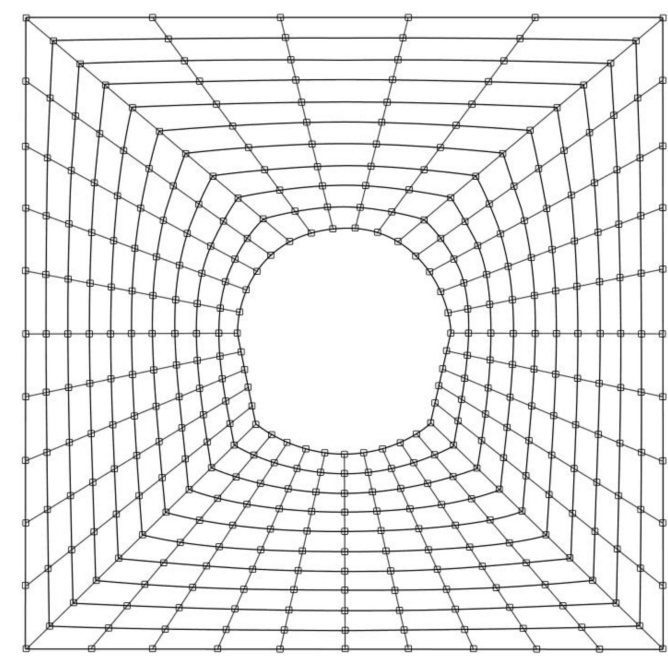

Fig. 8. Cross-Section of the Tunnel

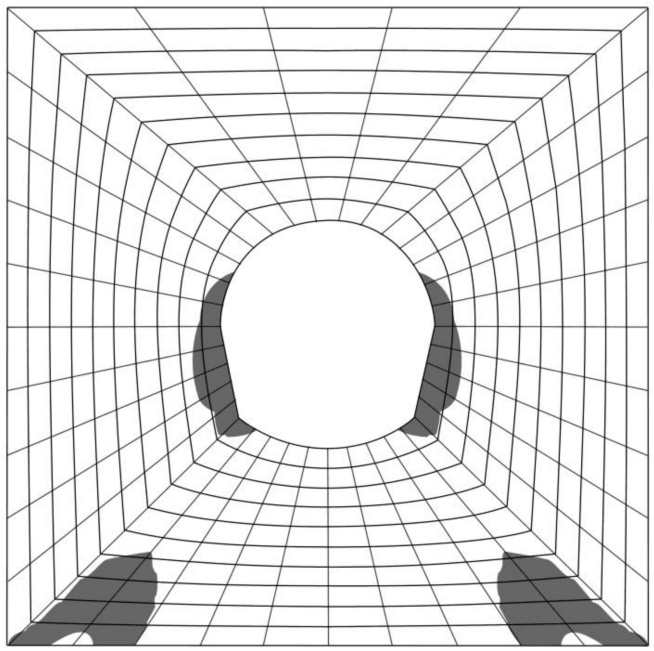

Fig. 9. Failure According to Von-Mises Criteria 


\section{Acknowledgement}

The authors would like to acknowledge the contributions made by Prof. Vutukuri.

\section{References}

1 Gysel M, Design of tunnels in swelling rock, Rock Mech Rock Eng, 20, (1987), 219-242, DOI 10.1007/BF01024643

2 Kovari K, Amstad C, Anagnostou G, Design/construction methodstunnelling in swelling rocks, Key questions in rock mechanics, In: Cundall PA (ed.), Balkema; Minnesota, USA, 1988, pp. 17-32.

3 Anagnostou G, A model for swelling rock in tunneling, Rock Mech Rock Eng, 26, (1993), 307-331.

4 Anagnostou G, Pimentel E, Serafeimidis K, Swelling of sulphatic claystones, some fundamental questions and practical relevance, Geomech Tunnel, 3, (2010), 567-572, DOI 10.1002/geot.201000033

5 Characterization of Swelling Rock, International Society for Rock Mechanics, (1983).

6 H Einstein, Suggested methods for laboratory testing of argillaceous rock, Commission on Swelling Rock, Int J Rock Mech Sci Geomech Abstr, 26, (1989), 415-426.

$7 \mathbf{H}$ Einstein, Comments and recommendations on design and analysis procedures for structures in argillaceous rock, Commission on Swelling Rock, Int J Rock Mech Sci Geomech Abstr, 31, (1994), 293-306.

$8 \mathrm{H}$ Einstein, Suggested methods for rapid field identification of swelling and slaking rocks, Commission on Swelling Rock, Int J Rock Mech Sci Geomech Abstr, 31, (1994), 545-548.

9 Wittke W, Essen, Germany, Stability analysis for tunnels: fundamentals Verlag Glückauf GmbH, 2000, ISBN 9783773913241.

10 Lo KY, Micic S, Lardner T, Janes M, Geotechnical properties of a weak mudstone in downtown Calgary, In: Tonkin MJ (ed.), Canadian Geotechnical Society, 2009, pp. 454-462.

11 Mohajerani M, Delage P, Monfared M, Tang AM, Sulem J, Gatmiri B, Oedometric compression and swelling behaviour of the CallovoOxfordian argillite, Int J Rock Mech Min Sci, 48, (2011), 606-615, DOI 10.1016/j.ijrmms.2011.02.016

12 Dawei M, Bjørn N, Ming L, Analysis of loading effects on reinforced shotcrete ribs caused by weakness zone containing swelling clay, Tunnel Underg Space Technol, 26, (2011), 472-480, DOI 10.1016/j.tust.2011.01.004

13 Barla M, Numerical simulation of the swelling behaviour around tunnels based on special triaxial tests, Tunnel Underg Space Technol, 23, (2008), 508-521, DOI 10.1016/j.tust.2007.09.002

14 Madsen FT, Suggested methods for laboratory testing of swelling rocks, Int J Rock Mech Min Sci Geomech, 26, (1999), 211-225.

15 Cheraghi Seifabad M, Tunnelling in swelling ground, Pacific Rocks, In: Liebman M, Doe T (eds.), Balkema; Seatle, USA, 2000, pp. 1115-1117.

16 Nisa II. Cranes Software, Inc. 1133 E Maple Road, Suite 103, Troy, Michigan 48083,2000 